\title{
Critical personal reflections on professional development within a complex learning environment
}

\author{
Deborah Prescott \\ School of Education, Charles Darwin University, Australia \\ deborah.prescott@cdu.edu.au
}

Keywords: narrative inquiry, learning, online, sustainability, collaboration, complexity

\begin{abstract}
This article presents my professional reflections about what I am learning as a team member of two large units in the Graduate Diploma of Teaching and Learning. Critical personal reflection and narrative analysis are used to explore my professional learning journey, particularly in relation to my 'primary colleague', the most experienced team member. This narrative critically reflects on tensions between my developing understandings about learning and teaching in higher education and how learning best takes place. The literature supports learning and teaching approaches that disrupt the status quo, foster complexity and cultivate true collaboration and transdisciplinarity.

Guiding my reflections is how I have been helped by my primary colleague and, in turn, how I may be able to help others towards more collaborative, reflective and transdisciplinary workplace practices in spite of working within isolating course parameters. How can we each make space (physical, virtual, collegial, temporal and mental) to engage in collaborative workplace practices that turn the focus of teacher education more towards complex, transformative learning? Collaborative work is time-consuming and, in my experience, thoroughly effective and deeply satisfying.

Collegial dialogue within my team has occurred in the complex context of improving the learning of our students and has included such wide-ranging topics as: philosophies of learning, effective pedagogies, environmental sustainability, the scholarship of learning and teaching, political and industrial issues, and transformations to teacher education and schooling. These conversations deepen what I am able to bring to my students' learning and create synergies between professional reflections and student learning processes that inform each other.
\end{abstract}

\section{The complex learning environment}

The Graduate Diploma in Teaching and Learning (GDTL) is a mature, one-year, full-time course in the School of Education that is approaching the end of its life cycle. The Australian Institute for Teaching and School Leadership (AITSL) mandated in 2011 that any pre-service teacher course must be a minimum of 18 months in order to be nationally accredited in Australia. Semester 1 , 2014 is the last intake of students and we will teach out the course through Semester 2, 2016.

Charles Darwin University is fortunate that the GDTL accreditation was extended several times because it attracts many students. This highly diverse cohort comprises students who: bring the full range of previous degrees (e. g. Visual Arts, Accounting, Outdoor Education, etc.); live in Australia and in other parts of the world; are about $85 \%$ external enrollees; fulfil professional 
placements in the entire range of schooling levels and environments; are almost all matureaged and relative newcomers to learning technologies, and; juggle home, work, leisure, workintegrated learning and study. I am constantly amazed at the demanding schedules that these students set for themselves to succeed at this course within a one-year timeframe.

For seven years I have been team-teaching with the same full-time lecturer (my 'primary colleague') in two large units entitled Teaching the Curriculum/Integrating Literacy and Teaching the Curriculum/Integrating Numeracy. From time to time we have been allocated an additional one to two part-time lecturers and up to three casual markers. Under current workload guidelines, one unit with the enrolment of 450 (enrolments in one of these units recently reached 650) calls for at least four full-time staff for a year of teaching, which is applying a notional EFTSL (effective full-time student load) of 30 . However, both my primary colleague and I had considerable, additional work allocations.

In addition to workload considerations, these units (two of three non-practicum-based units in the GDTL) carry a wide-ranging brief that normally would be spread across many disciplines and topics, like sociology, educational policy, educational inequalities, and history of education. As well as the diverse range of student backgrounds and teaching situations, the units also address relevant curriculum frameworks from multiple jurisdictions and pedagogical approaches, literacy (and digital literacies), numeracy, reflective practice, ICT in education, philosophy of education, professional literacies, and problem-based learning. Furthermore, either unit can be the initial or terminal unit for students and that requires extra support (on entry) and requests for early grade release, for example (on exit).

Accordingly, staff assigned to one or more of these complex, multi-dimensional units are consulting with each other on a daily basis - formally and informally, in person or online, in or outside business hours - on teaching approaches, responding to student need, consistent management of issues, unit and assessment re-design processes, and ongoing moderation. I found this team work one of the most satisfying aspects of working on these units.

In spite of these challenging parameters, our team has had a consistently low rate of 'assessment continuing' marks (requiring lengthy administrative follow-through), a negligible failure rate, few problematic complaints, a relatively low number of extension requests, and manageable email and phone contacts. When marking, it is important that the responses to the assessment tasks are widely varied - fore-fronting context - with the result that plagiarism is difficult to execute and students are publicly sharing their entire assignments for peer review before and after staff assessment!

\section{Guiding questions}

The questions guiding my reflections are how to help my colleagues be more effective teachereducators, address big questions (not always administrative ones), reduce frustration through more collegiality (adopt less isolated work practices), and align the way we do business with our educational philosophies (resist simplistic responses to complexities). Because I have been helped and inspired - enormously - in my professional work, I want to relate how my increased understandings could be used to help other staff members towards similar experiences. However, this isn't as easy as a simple list of instructions!

One way that my primary colleague and I have conspired to 'spread the good news' about our work is to recruit different staff members to be part of our team. So far, over seven years, we have had four additional permanent staff working within these units and experiencing innovative assessment and learning practices. The process of collaborative planning and the 
innovations springing up in our meetings (and the research between planning meetings) has been successful because it has capitalised on the need-to-know, just-in-time basis rather than an add-on to teaching and research priorities.

\section{Transformative literature}

In this section I examine the literature in different contexts supporting epistemological shifts in teacher education and pedagogical approaches (for both teacher education and schools) which would have a profound positive effect on learning for the $21^{\text {st }}$ century. I chose resources which disrupt the status quo and enact a philosophy which better prepares us to face an uncertain world. My primary colleague introduced me to many of the texts that I have examined in this critical personal reflection.

\section{Changing tertiary environment}

One of the strong themes underpinning our professional conversations has been how our pre-service teacher education could more accurately reflect transformative learning. Morin's Seven complex lessons in education for the future (1999) is a seminal work that should be central to teachers' reflections. Reading Morin's 63-page book repeatedly over the years, I have recognised many of the 'complex lessons' we have used in redesigning our units: detecting error and illusion, principles of pertinent knowledge, teaching the human condition, earth identity, confronting uncertainties, understanding each other, and ethics for the human genre. Not only does Morin address teachers' and teacher educators' work, but he also believes environmental concerns should be fundamental. So far, in my experience, environmental sustainability (I use this label for its familiarity, not necessarily its accuracy) has not been fore-fronted in our teacher education courses. Later in this article, I note more resources about the importance of making education for environmental sustainability integral to teacher education.

Major (2011) records a self-study in a New Zealand context about her teaching also in a Graduate Diploma of Teaching course. She clearly articulates the tensions she feels in reconciling the philosophy underpinning her pedagogical approaches with the philosophy of the 2007 implementation of the NZ curriculum and its inquiry-based directive, in particular. I found many parallels to the contradictions I observe in pedagogical practices in higher education that do not align with new conceptualisations of knowing.

In a nursing education context, Northedge (2006) explores the historical picture about how tertiary education has struggled making the transition from teacher-led courses to studentcentred learning. This was brought home to me earlier this year, when I attended a seminar on 'Flipped Classrooms' (Educause, 2012), that tertiary educators are still struggling with didactic pedagogies versus student-led learning methods. My experience with TAFE and adult ESL pedagogies set me up for pedagogical approaches which are more aligned to a 'flipped classroom' and I was surprised to learn that this wasn't so with many tertiary educators.

Davis, Sumara \& Luce-Kapler in Engaging Minds (2008), take this debate between teachercentred or student-centred pedagogies a leap forward suggesting that the notion of 'centre' can be an event - not a person or object. Teachers should deliberately design the learning event so that people and ideas 'bump into' each other around this 'emerging possibility' (Davis, et al, 2008, p. 200). Our assessment tasks - events - in our GDTL units have allowed emerging possibilities to arise in student-led discussions in a decentralised interactive structure. Active learning develops over the semester with about 200 students regularly participating in discussions. What is the critical mass that allows students' ideas to bump into each other in the context of an online Discussion Board? In other small, teacher-centred units, the likelihood of lively discussions around an emerging possibility is reduced. 
Davis, et al (2008) mention Fernandez \& Yoshida's (2004) Lesson study: A Japanese approach to improving mathematics teaching and learning. They present a collaborative and dialogic approach to planning maths lessons, helping me start to articulate both the approaches my team and I use to plan tutorials and seminars, and more deeply understand the assessment tasks that we set for our students, which include 'illustrative classroom dialogue' (a very insightful aspect of the tasks). Our team's approach is certainly collaborative: in short, intense periods, we revisit what students understood in sessions previously; the directions students are taking in their discussions currently; what students need to know now in order to complete the assessment tasks successfully; how to meet students' needs in a session. This just-in-time planning is thoroughly dialogic, contextual and reflexive in its focus.

There is another level to Lesson Study (as conceived by Yoshida \& Fernandez) that is missing in our School context and that is course planning collaboration. The Japanese schools referred continuously to the school priorities and vision in order to keep all teachers working on collective goals. In our School, we are overwhelmingly individuals, working on separate units, without reference to the overall principles or course goals to guide us purposefully. My team's units are minor exceptions.

Ramsden (2003) makes the important point that changing the nature of tertiary teaching does not fall just to the individual lecturer: "Focusing on this level alone is likely to create frustration, conflict and, ultimately, regression to the status quo" (p. 9). This is precisely what, I believe, is happening in our School as we struggle with workloads and multiplying units and courses in a tightening economic environment. In my team, we have been able to continually improve our learning and teaching because of our collective reflection and innovation.

Online learning and teaching is a strong reality in higher education especially at CDU. Relying on our learning management system (even the term 'management' mitigates 'learning') for innovation frustrates attempts to turn the spotlight onto transformative pedagogies. Many of the support tools encourage didactic teaching.

\section{Learning and teaching for social change}

The problems in schools highlighted in the media haunt teachers and teacher educators: Indigenous students showing marginal NAPLAN improvement; crackdowns on professional teaching standards; rising costs of education, etc. The solutions put forward, however, are short-term, mechanistic, under-funded and political.

Engaging Minds by Davis, Sumara \& Luce-Kapler (2008) is my new 'bible'. They highlight emergent insights rather than perpetuate the myths of 'precise definitions, unambiguous classifications... and irrefutable logic'. By their own admission, they aim to 'unsettle popular beliefs about formal education' via the core themes, 'complexity, interdependence, emergence, and transformation' (p. 5).

I chose Engaging Minds as the prescribed text for a new unit 'Researching Classroom Practice' because it brings attention to why our assumptions about learning and teaching need to be disrupted, particularly as applied to teacher education. Part C, 'Teaching frames,' in this text brings some insight to my professional reflections. The authors ask, for example, 'How can teaching simultaneously be about disciplining and empowering (p. 158)?' These are the kinds of questions that supply the 'disorienting dilemma' or 'enabling constraint', setting the scene for discussions around a rich, problem-based task, and enabling process-oriented (versus content-driven) learning. Other stakeholders in the unit, 'Researching Classroom Practice', did not endorse my choice of text. The focus, it was thought, should be on what is commonly mistaken for 'researching'; that is, how to distinguish between qualitative and quantitative methodology, for example, and how to write up a research report. 
Northedge (2006) asks the same questions as Davis, Sumara and Luce-Kapler - What is knowing? Learning? Teaching? - in the context of a large, diverse course in nurse education. Northedge defines learning as 'a process of becoming increasingly competent as both a user of various specialist discourses and a participant within the relevant knowledge communities' (p. 19) which resonates within my personal journey. His emphasis on creating discursive environments affirms the approach we have taken in our conversations and our units.

I wrote the paragraphs above (Learning and Teaching for Social Change) before reading Edwards-Groves, Anstey and Bull's (2014) book, Classroom Talk, and immediately recognised what I had long suspected: there is a strong link between enabling school classroom talk, collaborative professional learning in pre-service teacher education and the transformation of teacher practice. The authors are adamant that this transformation requires continual collaboration within strong learning communities and dogged research into teaching practice. My MEd thesis (Prescott, 2006) instilled a deep appreciation for the role of talk in learning, thinking and writing. Now, in the GDTL units, I can see that not only does dialogic learning occur within our teaching team, but it also better ensures that our students (and their students) will have the opportunity for more dialogic learning in spite of a strong legacy of didactic culture in tertiary learning and teaching.

Environmental sustainability is an abiding force in my life. I am intrigued by Bamford's article (1999), From environmental education to ecopolitics: Affirming changing agendas for teachers. His position is that relationships between humans and the physical environment are the bases for holistic curriculum (like Morin and Jardine) in order to examine complex differences (such as power relationships) to improve the ways all creatures live in the world. As soon as teachers focus on the processes of learning, resist the simplistic, mechanical world view predominating in education, and draw heavily on the transdisciplinary and complex community contexts, teachers 'move into realms that are counter to existing dominant values' ( $p$. 170). But teachers themselves 'legitimate dominant cultural values...' and '...need to escape their own enculturation' if they are to genuinely address environmental concerns (p. 171). Recently, I have become convinced that in order for behavioural changes to 'stick', teachers need to apply pedagogical approaches akin to the approaches we have applied in our units. This (environmental) layer of meaning to transformative pedagogies is driving much of my reading currently.

David Jardine's Pedagogy Left in Peace (2012) was my (continuing) introduction to philosophers in education. The main premise of the book is that education requires free spaces to keep open possibilities of learning and teaching. Jardine makes some of the same points as Morin (1999) does: learning is context-dependent, ecological concerns are critical to how we come to know interrelatedness and wholeness, fragmentary disciplines are incapable of helping us towards deep knowing, uncertainty and impermanence must be accounted for in learning and teaching. Some of my 'ah-ha' moments came when I recognised (in this book and others) what my primary colleague had conceived of, planned for, insisted on and implemented in the units that we taught together.

I would like to offer an illustration of how we have created space for creativity. Our students often demand they be given an exemplar of a 'good' assignment so that they will know 'what we want'. We have consistently resisted publishing past assignments, partly because the assessment tasks change every semester and partly because Jardine says that the demand to be told is how truths remain hidden - we need to practice and cultivate knowing in order to know. Jardine says that 'you cannot practice this knowledge by yourself and alone and only within the confines of the devices you have already mastered because this is not how this knowledge is held in the world' (p. 126). Over time, becoming more experienced in the process of learning, makes you more able and willing to be 'left in peace' to let this process unfold anew. This place, however, is anything but peaceful and I know that my primary colleague is never at peace in his knowing. 


\section{Personal knowing unfolding}

My personal narrative and critical reflection is grounded in Dewey's philosophy of education and his belief that we learn from experience and reflection on experience. I have narrated parts of my professional learning journey with a critical reflective lens and have attempted to capture memories over the past five years without systematic data collection.

Clandinin \& Connelly (2000) also emphasise reflection in narrative enquiry in teacher education. I have sought patterns in this narrative that are meaningful towards my changing professional practice. Clandinin \& Connelly's research framework helps me find these patterns and position my narrative within the 3-dimensional inquiry directions (inward, outward, backward, forward, and place-situated) it takes.

Construction (Davis \& Sumara, 2012, suggest that construing is a more accurate translation from the French) of professional knowledge is understood as a relational and interactive process between colleagues and the contextual teaching aspects. Critical personal reflection, as I have experienced it, challenges simplistic notions of being a university lecturer - an expert of a discrete discipline working in isolation with a set of learning outcomes. Critical personal reflection validates individuals' experiences and accounts for the differences brought by individuals to the teacher education setting. My professional journey, in these units within this team, has affirmed that in a collective learning environment, 'Ideas can be sustained for a longer time, a greater variety of interpretations can be introduced, a broader pool of experiences can be drawn on. Two heads can be much better than one' (Davis, Sumara \& Luce-Kapler, 2008, p. 69).

The act of writing this article has been important in reflection - writing as a form of analysis is difficult work (Altrichter, Posch \& Somekh, 1993). Articulating the learning I have experienced is the active process of thinking-in-action and thinking with others:

Through respectful dialogue and conversations with multiple others, individuals come to know themselves and others, to know what they know and to construct professional identities (Beattie, 2000, p. 4).

For the most part, collegial interaction, teamwork, dialogic learning, follow-up readings, university policy, etc. has been pursued in the context of our work in the Graduate Diploma units. Although these discussions have opened up whole new areas for me, the immediate use of new knowledge in marking assignments, responding to student requests, writing reports, composing assignment tasks and marking sheets, for example, have been an extremely positive and stimulating learning experience for me.

\section{Critical personal reflections}

In 2009 when we started working together, my primary colleague suggested we set about transforming the units systematically. We drew a mind map of the unit outcomes and aligned them (Biggs and Tang, 2009) with the assessment tasks and learning activities. Being systematic seems counter-intuitive to creativity and innovation but as my primary colleague and I (re)created the units, we talked about the design process, reflexivity and iterativeness. (I just looked up the definition of iterative: it has its roots in mathematics - recursive, and linguistics - frequentative, which are two areas of study by my primary colleague. This small parenthetical fact not only exemplifies iterativeness but also emphasises the transdisciplinary nature of knowledge connections that we all need to foster.)

A systematic approach to teaching does not preclude learning outside of the plan. In trying to come to terms with an apparent contradiction in my mind about how an approach to teaching can be systematic and still flexible, creative, innovative, and open to new and unanticipated 
areas, our conversations touched on philosophy, engineering and ICT (additional areas my primary colleague studied comprehensively). Teachers need to have a strong philosophical basis in which to ground their pedagogical choices, articulate rationale for their teaching decisions, and make spur-of-the-moment responses that are based on underpinning ideals. Davis, et al, say, 'Knowing and doing are not different phenomena' (2008, p. 6). Do teacher educators make daily decisions based on their philosophies of learning and teaching? I am working on it.

I wondered aloud to my primary colleague about some of the rationale for doing things a little differently to the norm and copied his well-conceived learning designs. It was much later when I could articulate rationale myself that my professional development probably started to lurch forward.

The engineering domain helped frame our conversations about the design process and how non-linear it is, contrary to the simplistic models available in some units for pre-service teachers. We have tried to 'de-linearise' Learnline (CDU's online learning platform) to help students understand the complexity, iterativeness and connectedness of the themes running through our units. Indeed, our conversations have spanned the whole range of subject disciplines to explore cross-, multi-, inter-, and trans-disciplinarity (the approach which, we decided, is most fruitful for learning).

My primary colleague used the Johari Window for a lecture on professional reflection for Teaching the Curriculum 2 /Integrating Numeracy unit. I will attempt to use the framework of the Johari Window to illustrate aspects of my professional reflections in this paper. I found it more difficult than I first thought to fill in the four quadrants (Fig. 1). The descriptors accompanying the arrows on the diagram were particularly helpful in analysing the dynamic nature of my professional reflections.

Figure 1: The Johari Window

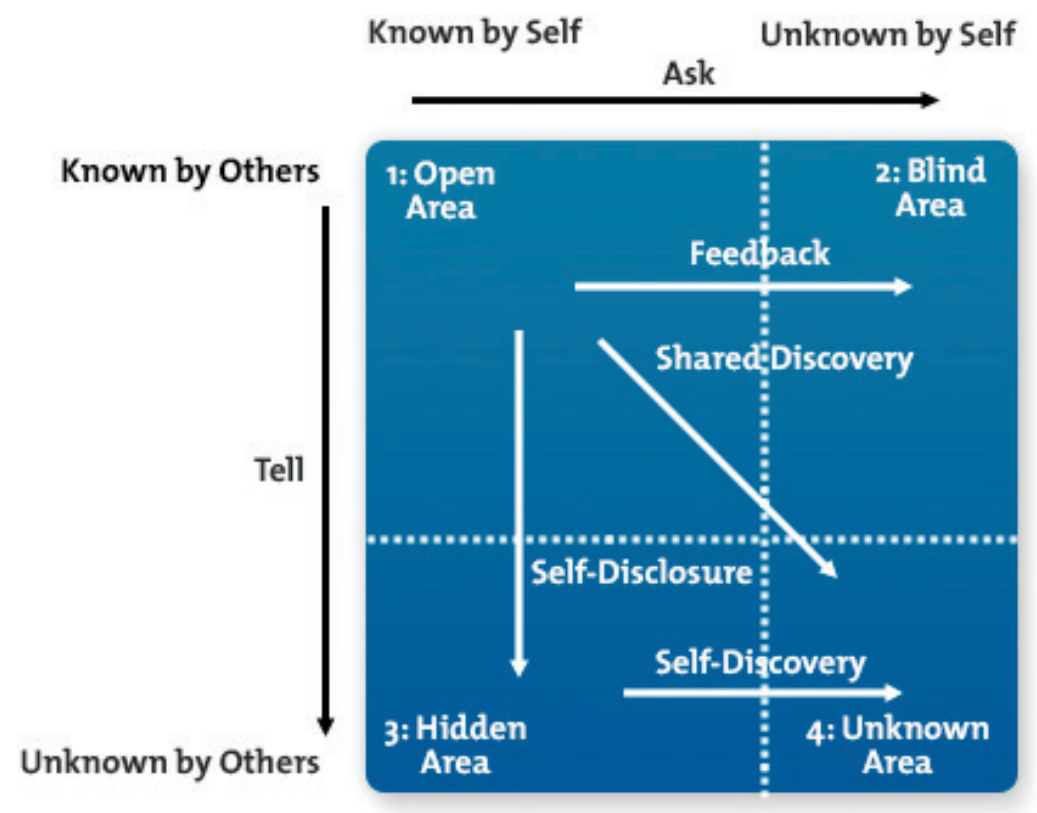


The object of the Johari Window is to increase the size of the 'Open' area through sharing discoveries and insights and working collectively. In the 'Open' area, some aspects about me are publically known: involvement in environmental sustainability activities; literacy and EAL/D teaching background; Master of Education (Teaching English to Speakers of Other Languages); focus on pedagogy in transformative education; interest in Indigenous teacher education. I find strong synergies between all of these areas for research, professional development and teaching responsibilities.

The 'Blind' area, I feel, includes most of the conversation topics that my primary colleague and I covered in the past 5 years whilst working on innovative approaches to learning and assessment tasks in our units. He introduced me to enabling features of technologies such as transclusion ${ }^{1}$ and stretch-text documents (e.g., Tiddlywiki) for student assignments and collaborative programs for managing large student cohorts (e.g. 37 Signals, Formstack and WebMerge).

In addition, I became aware of how my primary colleague collected data over time in order to support decisions. At the beginning of 2012, I decided to revive Academics Anonymous (an informal group that shares research ideas fortnightly) and wondered out loud to my primary colleague what tack to take. To my surprise, he produced almost two years of invitations that I had sent out and had detected patterns amongst them!

The importance of context was emphasised again and again in relation to our planning for learning activities, assessment design and assignment marking. During the development of our units I felt as if 'context' took on a life of its own and became the overriding factor in discussions with students, in interpreting academic literature, and in my own research. Recently, I surprised myself by discovering, whilst reading my minor thesis (2008) on Indigenous student classroom talk, that I had recognised the importance of context as well. So maybe this belongs in the 'Open' area of the Johari Window instead!

Conversations amongst our team members spanned the history of theorists and theories, evolution of Indigenous teaching approaches, narratives of philosophy development, logic, expansive learning, dialectical processes, complexity theories, communities of practice, activity theory, fractals, and cellular automata. Do I have a working knowledge of these complex topics? No, but I have begun.

Expansive learning and activity theory interest me most in the context of my own professional development. Engeström formulated the theory of expansive learning in 1987 and I learned of it in 2010 as my primary colleague and I reconceptualised a new BEd course. The wouldbe course was designed to cater to all pre-service teachers in whatever grade level and discipline area of teaching they aspired to - the unit 'Expansive Learning' was compulsory for all. I understand expansive learning as a concept of activity theory (Fig. 2). Theorists are (re)generating activity theory to incorporate: collective action to tackle pressing issues of humankind; a sense of local and global history; contradictions or 'wicked' problems (Rittel \& Webber, 1973); and expansive learning.

1. Transclusion in computer science is the inclusion of a document (or part thereof) into another document by reference. Transclusion embodies modular design by allowing data to be stored (corrected and updated) only once and viewed in different contexts (Wikipedia, 05 December 2013). 
Figure 2: The structure of a human activity system

Instruments:

tools and signs

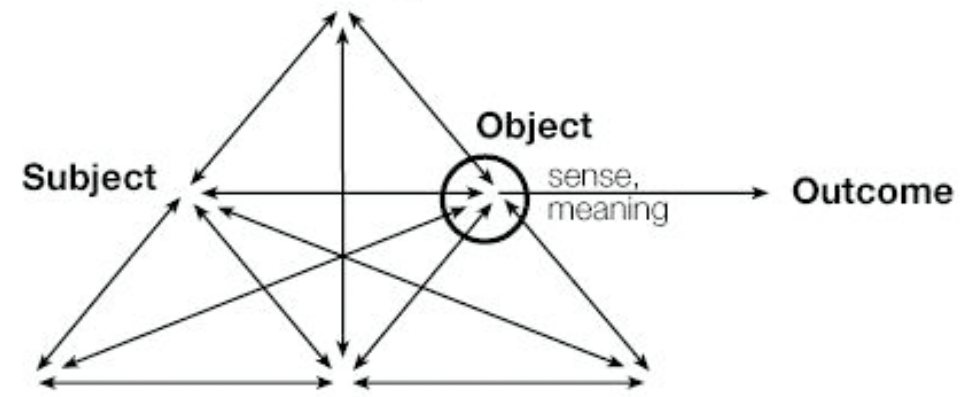

Rules Community Division of labor

Source: Engeström, 1987, p.78

In expansive learning cycles, 'nobody knows exactly what needs to be learned' (Engeström \& Sannino, 2010, p.3) and we must learn new forms of activity for which there is no competent teacher. Our pedagogies must reflect this complexity, uncertainty and 'double bind' (Engeström, 2001, p.138). Expansive learning - akin to the approaches we have applied in our units - is more likely to be sustainable (in more than one way).

Amongst other 'Blind' areas, I have become aware of how important it is to invoke policy in making even the most mundane decisions about student extensions, for example. Most staff members regard policy as an onerous administrative necessity and one that is rarely called upon in routine tasks. However, answering student emails in accurate, considered, and formal (but not heavy-handed) language, demonstrates to the student that their individual circumstances are understood, are being taken into account, and there are logical and fair options available. These comprehensive emails take time to compose but I believe this one strategy alone minimises our email communication to a large extent. Once written and filed, they can be selectively recycled. When I compare notes with other lecturers, they exclaim, 'You must be swamped with emails and phone calls!' This reaction is indicative of workload expectations and to disparities between student and lecturer expectations of learning and teaching in higher education.

'Hidden' area (Fig. 1) aspects may include some things that I have chosen not to tell my team members because I am ashamed to have made some bad administrative decisions. However, I am fairly self-disclosing, so they may know more than I think they do. I am still uncomfortable in publicly sharing my insights outside my immediate team. I would like to push these boundaries and work harder at articulating my lingering doubts regarding using mark sheets instead of rubrics, for example.

The 'Unknown' area tends to be institutional elements and this formed an important aspect of patterns I detected with the help of my primary colleague. Institutional elements include assumed workplace practices that are deeply ingrained and, thus, very difficult to change or even call attention to. Examples of 'unknown' areas that need to be collectively examined to expose inefficient work elements in the institution are: how to tackle plagiarism without (more) layers of electronic detection; how to minimise AC (assessment continuing) marks; how to maximise transdisciplinary pedagogies through innovative course structure. Another illustration is the decreasing opportunity to work in the fulfilling environment of teams (as I have experienced), which, in turn, increases the feeling of individual isolation. Jardine (2012), 
Engeström \& Sannino (2010), and Morin (1999) strongly emphasise the crucial importance of recognising and drawing on the human need for participatory learning and teaching and 'collective cognition' (Davis, Sumara \& Luce-Kapler, 2008, p. 68).

The 'unknown' area is gradually being whittled away (and simultaneously expanding!) the more topics that we delve into.

My primary colleague has an enviable depth of knowledge in environmental sustainability. In our conversations, we discussed the imperative to change the structure of Western hegemonic economic systems in order to sustain change in people's behaviour. (Social systems, too, are integral but generally more frequently discussed.) These conversations led to my emerging understanding that didactic teaching does not support the behavioural changes needed in order for education for environmental sustainability to 'stick'. Bamford (1999) refers to Bowers \& Flinders (1990) where they suggest that the technicist approach (which, like didacticism, is still very much the dominant approach to teacher education and in classrooms) is the antithesis of environmentally responsive pedagogy. They define the technicist approach as one where there is compartmentalisation of subjects and students, measurement and testing of stable and well-defined knowledge, management and control, and individualised instruction. It may be too simplistic to make direct contrasts, but environmentally responsive pedagogy is more aligned to transdisciplinarity, forming discourse communities and networks, building on a strong language focus, and negotiating tasks and activities in democratic classrooms. I continue to try to articulate in more detail pedagogical approaches to environmental sustainability that are more likely to result in robust behavioural changes.

\section{Patterns in reflections}

The main theme running through the past five years is that of collegiality. Whenever my primary colleague started a conversation, I felt as if it was a huge investment on his part and a privilege to be part of the dialogue. When I offered some observations within the topics we explored, I found that he was a good listener as well as a thoughtful speaker - he was interested in my interpretations of things and how I was constructing meaning. I have tried to extend similar experiences to other colleagues.

Dialogic culture is even more difficult to establish amongst students on line within their tight schedules. Our problem-based assignments, however, triggered rich discussions amongst about one-third of students and resulted in some lasting student-student relationships. More importantly, participating students discovered that collegial dialogue and helping each other stimulated and maintained their own learning.

Time underpins quite a lot of the problems and solutions in my reflections. The time it takes to work within a team of this calibre and to explore ideas to the extent we did is a severely limiting factor with the workloads we carry. However, time spent in conversations usually led to smarter ways of assessing or marking, ideas for research, broader perspectives, keener insights.

I am becoming aware of just-in-time teaching and learning. In our units, we emphasise the learning process over content knowledge. My learning happens sometimes just in time to deal with our students' learning as it happens and questions as they arise. This means that we have to be watching, summarising, conversing and responding to student learning and not necessarily planning every detail of a tutorial, for instance, far in advance. To do this well takes a widely-read, broadly-experienced teacher (like my primary colleague). To do this well takes pedagogical free spaces (Jardine, 2012) where unanticipated - and thoroughly legitimate and meaningful - learning directions are likely to arise within complex tasks. 
Another pattern in my professional learning, supported by the literature (I was relieved to learn), is copying. Davis, Sumara \& Luce-Kapler (2008) refer to copying as a legitimate form of professional development and is typified by "nuanced give-and-take, ....rich contextual detail, ....ample opportunity to mimic, and ... freedom to err without worry of reprimand" (p. 216). This strongly resonates with me but the valuable learning experience doesn't end there. I, then, have to be in the professional world, in my own particular way, in a context of my own making, and creatively re-enacting my own specialised discourse using my own voice and agency.

We are working in a tertiary education environment, the changes to which are coming from marketing surveys, new political leaders, various interpretations of student needs, schooling demands, curriculum implementation and research priorities - the changes are not necessarily coming from solid academic studies, deep reflective practices or genuine transdisciplinary collaboration. The changing environment is nothing new to the School of Education or university - and neither is our response to change. We allow other institutions to dictate the approach we take when research shows it isn't how students best learn. We allow ourselves to work in isolation when collaboration is more productive, satisfying and reflects a more accurate world view.

\section{Work in progress}

Although I have given some examples of how I have been helped in my university teaching and how I may progress my personal reflective journey, I recognise that this is a thoroughly personal and contextualised account and others must actively personalise and contextualise their own ways to be helped.

Although I cannot control how others engage in reflective practices, I can contribute by holding consistent Academics Anonymous sessions and inviting people to develop and maintain collective mindsets and collegial dialogues; keeping up momentum on projects which might be sidelined because of other priorities; actively pursuing my own directions and possibilities for research, now that I feel more confident about my contributions.

Reconciling the tensions between individual agency (issues of other staff members) and the collective need (furthering transformative learning) is an ongoing source of reflections for all academic staff.

\section{Acknowledgements}

I am grateful to my primary colleague for his time and effort in persevering with me in my professional journey. I would also like to thank other colleagues who have listened to me over the years and helped me articulate my learning.

\section{References}

Altrichter, H., Posch, P. \& Somekh, B. (1993). Making teachers' knowledge public. Teachers investigate their work: an introduction to the methods of action research. London: Routledge.

Bamford, B. (1999). From environmental education to ecopolitics. Affirming changing agendas for teachers. Educational Philosophy and Theory, 31(2), 157-173.

Beattie, M. (2000). Narratives of professional learning: Becoming a teacher and learning to teach. Journal of Educational Enquiry, 1(2), 1-23. 
Biggs, J \& Tang, C. (2009). Teaching for Quality Learning at University: What the student does. New York: McGraw-Hill Society for Research into Higher Education and Open University Press.

Clandinin, D. J. \& Connelly, F.M. (2000). What do narrative inquirers do? In Narrative inquiry: experience and story in qualitative research. San Francisco: Jossey-Bass Publishers.

Davis, B., Sumara, D. \& Luce-Kapler, R. (2008). Engaging minds: Changing teaching in complex times. New York: Routledge.

Davis, B. \& Sumara, D. (2012). Fitting teacher education in/to/for an increasingly complex world. Complicity: An International Journal of Complexity and Education, 9(1), 30-40. Retrieved from http://ejournals.library.ualberta.ca/index.php/complicity/article/view/16531/13213.

Educause Learning Initiative, (February, 2012). 7 things you should know about flipped classrooms. Retrieved from http://net.educause.edu/ir/library/pdf/eli7081.pdf .

Edwards-Groves, C., Anstey, M. \& Bull, G. (2014). Classroom Talk: Understanding dialogue, pedagogy and practice. Newtown, NSW: PETAA (Primary English Teaching Association Australia).

Engeström, Y. (1987). Learning by expanding: an activity-theoretical approach to developmental research. Helsinki: Orienta-Konsultit.

Engeström, Y. (2001). Expansive learning at work: toward an activity theoretical reconceptualization. Journal of Education and Work, 14(1), 133-156. DOI: 10.1080/13639080020028747.

Engeström, Y. \& Sannino, A. (2010). Studies of expansive learning: Foundations, findings and future challenges. Educational Research Review, 5(1), 1-24. DOI: 10.1016/j.edurev.2009.12.002.

Jardine, D. (2012). Pedagogy Left in Peace. London: Continuum International Publishing Group.

Jardine, D., Clifford, P., Friesen, S. \& LaGrange, A. (2001). Back to basics: rethinking what is basic to education through an interpretive study of the work of teachers and students in elementary school classrooms. The Alberta Journal of Educational Research, 47(2), 187-190. Retrieved from http://ajer.synergiesprairies.ca/ajer/index.php/ajer/article/view/255/247.

Kitchenham, A. (2008). The evolution of John Mezirow's transformative learning theory. Journal of Transformative Education, 6(2), 104-123.

Major, J. (2011). Changing pedagogical practice in teacher education: negotiating the spaces between realism and relativism. Studying Teacher Education, 7(3). Retrieved from http://dx.doi.org/10.1080 /17425964.2011.617126

Mind Tools (2014). The Johari Window. Retrieved from http://www.mindtools.com/CommSkll// JohariWindow.htm.

Morin, E. (1999). Seven complex lessons in education for the future. Paris: UNESCO Publishing. Retrieved from http://unesdoc.unesco.org/images/0011/001177/117740eo.pdf.

Northedge, A. (2006). Rethinking teaching in the context of diversity: supporting social participation in a knowledge community. In G. Shaw (Ed.), Tertiary teaching and learning: dealing with diversity. Darwin, NT: Charles Darwin University Press.

Prescott, D.M. (2006). What happens during student talk in small reading groups in a Torres Strait high school? Unpublished Master's thesis. University of South Australia, Australia.

Ramsden, P. (2003). Learning to Teach in Higher Education. New York: Routledge.

Rittel, H.W.J. \& Webber, M.M. (1973). Dilemmas in a general theory of planning. Policy Sciences, 4, 155-169. 